
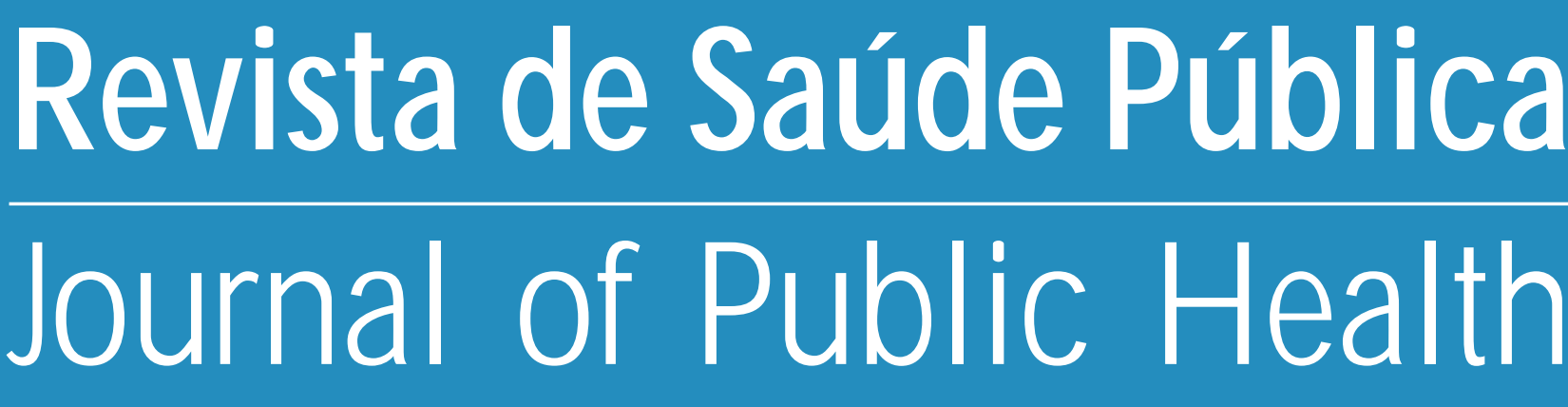

\title{
D isponibilidade de sorologia anti-HIV como um teste voluntário na rotina do atendimento pré- natal em unidades básicas de saúde
} Availability of voluntary prenatal HIV screening in primary health centers

\section{Fátima RAL Neves, Afonso DC Passos e Wagner L G ueleri}

Programa de DST/Aids da Secretaria Municipal de Saúde. Ribeirão Preto, SP - Brasil (FRALN); Programa de Atenção Integral à Saúde da Mulher da Secretaria M unicipal de Saúde. Ribeirão Preto, SP - Brasil (WLG); Departamento de Medicina Social da Faculdade de Medicina da Universidade de São Paulo. Ribeirão Preto, $S P$ - Brasil (ADCP) 


\section{Disponibilidade de sorologia anti-HIV como um teste voluntário na rotina do atendimento pré-natal em unidades básicas de saúde} Availability of voluntary prenatal HIV
screening in primary health centers

Fátima RAL Neves, Afonso DC Passos e Wagner L Gueleri

Programa de DST/Aids da Secretaria Municipal de Saúde. Ribeirão Preto, SP - Brasil (FRALN);

Programa de Atenção Integral à Saúde da Mulher da Secretaria Municipal de Saúde. Ribeirão Preto, $S P$ - Brasil (WLG); Departamento de Medicina Social da Faculdade de Medicina da Universidade de São Paulo. Ribeirão Preto, $S P$ - Brasil (ADCP)

Descritores

Cuidado pré-natal, organização e administração. Sorodiagnóstico da Aids, utilização. Promoção da saúde, organização e administração. síndrome de imunodeficiência adquirida, diagnóstico. Diagnóstico pré-natal, utilização.

\section{Keywords}

Prenatal care, organization and administration. Aids serodiagnosis, utilization. Health promotion, organization and administration. Acquired immunodeficiency syndrome, diagnosis. Prenatal diagnosis, utilization.

\begin{abstract}
Resumo
São apresentadas, de forma sucinta, as principais etapas cumpridas para a implementação da sorologia anti-HIV no atendimento às gestantes em unidades básicas de saúde. A partir de agosto de 1996, a realização de testes sorológicos para detecção do HIV passou a ser ofertada às gestantes atendidas em unidades básicas de saúde de Ribeirão Preto, SP, integrada a um conjunto de atividades rotineiramente executadas no atendimento pré-natal. Até o final de 1998, o teste sorológico foi aplicado em 68,3\% das 17.589 mulheres atendidas em pré-natal, resultando numa positividade de $0,76 \%$.
\end{abstract}

\section{Abstract}

A summary of the main steps towards the implementation of anti-HIV testing for pregnant women in the city is presented. Starting from August 1996, voluntary HIV testing became available to pregnant women seen at primary health centers in Ribeirão Preto, SP (Brazil), as part of the Prenatal Care Program. By the end of $1998,68.3 \%$ of the 17,589 women seeking prenatal care had been tested, resulting in a positivity rate of $0.76 \%$.
O aumento do número de casos de Aids entre mulheres tem sido um fenômeno observado em todo o mundo, refletindo-se em um risco progressivamente maior de transmissão vertical do vírus. Considerando-se que a adequada utilização da zidovudina reduz substancialmente tal risco, inúmeros países têm implementado a disponibilização da sorologia anti-HIV durante o período gestacional, com vistas a propiciar uma oportunidade de diagnóstico precoce da infecção e a conseqüente introdução de medidas profiláticas de efeito ${ }^{1,4.5}$.

Diferentemente de outras partes do Brasil, a epidemia de Aids em Ribeirão Preto apresentou, desde o seu início, um padrão epidemiológico em que se destacava 
a alta incidência entre mulheres ${ }^{3}$. A relevância desse fato levou o Programa Municipal de DST/Aids a instituir, a partir de agosto de 1996, o oferecimento da sorologia anti-HIV nas unidades básicas de saúde da cidade.

A implementação dessa atividade não se fez de maneira isolada, mas ocorreu de acordo com as diretrizes do Programa de Assistência Integral à Saúde da Mulher, norteada pelos princípios que regem o Sistema Único de Saúde. Assim, a sorologia anti-HIV foi disponibilizada de maneira integrada a um conjunto de atividades destinadas à promoção da saúde da mulher, incluídas a assistência pré-natal e ao puerpério, atendimento de queixas ginecológicas e orientações concernentes à contracepção, à prevenção e ao controle das doenças sexualmente transmissíveis e do câncer ginecológico.

O desenvolvimento do protocolo foi executado em parceria com o Hospital das Clínicas da Faculdade de Medicina de Ribeirão Preto, garantindo-se, em caso de positividade sorológica, a referência para um ambulatório de ginecologia e obstetrícia capaz de realizar um pré-natal diferenciado e de oferecer a medicação e o acompanhamento necessários.

Nas etapas iniciais do processo, optou-se por promover a sorologia em 16 das 32 unidades básicas que compõem a rede pública de Ribeirão Preto, as quais acham-se ligadas a 5 unidades distritais. A escolha dessas 16 unidades foi feita com base na avaliação de áreas que apresentavam números elevados de casos de Aids, deixando-se as restantes para uma implementação posterior. Encontros foram realizados com os respectivos gerentes e com os profissionais envolvidos, em cada uma das unidades selecionadas,

\section{REFERÊNCIAS}

1. Carusi D, Learman LA, Posner SF. Human immunodeficiency virus test refusal in pregnancy: a challenge to voluntary testing. Obstet Gynecol 1998;91:540-5.

2. Limata C, Schoen EJ, Cohen D, Black SB, Quesenberry $\mathrm{CP}$. Compliance with voluntary prenatal HIV testing in a large health maintenance organization (HMO). J Acquir Immune Defic Syndr Hum Retrovirol 1997;15:126-30.

3. Menesia, EO. Estudo epidemiológico sobre a síndrome de imunodeficiência adquirida (Aids) no Município de Ribeirão Preto, SP, Brasil [Dissertação]. Ribeirão Preto: Faculdade de Medicina de Ribeirão Preto, Universidade de São Paulo; 1999. com vistas à padronização de condutas e à atribuição de responsabilidades, particularmente no que se refere ao aconselhamento. A partir de abril de 1997, a disponibilização do teste foi estendida a todas as 32 unidades de saúde da cidade.

De agosto de 1996 a junho de 1998, foram realizadas as reações sorológicas pelo Instituto Adolfo Lutz, utilizando kits adquiridos pela Secretaria Municipal de Saúde (SMS), através de convênio entre a Prefeitura Municipal e o Ministério da Saúde, via Coordenadoria Nacional de DST/Aids. A partir de julho de 1998, a SMS optou por montar laboratório próprio, assumindo toda a demanda decorrente.

No período de 1 de agosto de 1996 a 31 de dezembro de1998 ocorreram 17.589 atendimentos de pré-natal nas unidades onde a sorologia anti-HIV se achava disponível. Desse total, 10.966 mulheres (62,3\%) concordaram com a realização do exame, resultado próximo àqueles relatados em alguns estudos recentes levados a efeito nos Estados Unidos e Canadá1, 2, 5. Positividade ao exame ocorreu em 83 pacientes, equivalendo a $0,76 \%$ (IC 95\%: 0,59 a 0,92). Tal valor situa-se bem acima dos percentuais de $0,19 \%$ e $0,025 \%$, encontrados recentemente em gestantes inglesas e escocesas, respectivamente ${ }^{4}$.

A presente descrição visa mostrar sucintamente o processo de disponibilização da sorologia antiHIV nas unidades da rede pública de Ribeirão Preto, o que representa uma das primeiras iniciativas de tal natureza no Brasil. Análises detalhadas acerca dos resultados obtidos nesses três anos de manutenção da atividade serão objeto de publicações futuras.

4. Nicoll A, McGarrigle C, Brady AR, Ades AE, Tookey P, Doung $T$ et al. Epidemiology and detection of HIV-1 among pregnant women in the United Kingdom: results from national surveillance 1988-96. BMJ 1998;316:253-8.

5. Patrick DM, Money DM, Forbes J, Dobson SR, Rekart $\mathrm{ML}$, Cook DA et al. Routine prenatal screening for HIV in a low-prevalence setting. CMAJ 1998;159:942-7.

6. Samson L, King S. Evidence-based guidelines for universal counselling and offering of HIV testing in pregnancy in Canada. CMAJ 1998;158:1449-57. 